\title{
Comparison of Oct4, Sox2 and Nanog Expression in Pancreatic Cancer Cell Lines and Human Pancreatic Tumor
}

\author{
Vahideh Assadollahi, ${ }^{1}$ Mohammadreza Gholami, ${ }^{1}$ Abolfazl Zendedel, ${ }^{2,}$ Zohreh Afsartala, \\ and Ferdoos Jahanmardi ${ }^{3}$ \\ ${ }_{1}^{1}$ Department of Anatomy, Lorestan University of Medical Sciences, Khorramabad, IR Iran \\ ${ }^{2}$ Department of Internist, Faculty of Medicine, Lorestan University of Medical Sciences, Khorramabad, IR Iran \\ ${ }^{3}$ Faculty of Medicine, Lorestan University of Medical Sciences, Khorramabad, IR Iran \\ *Corresponding author: Abolfazl Zendedel, Department of Internist, Faculty of Medicine, Lorestan University of Medical Sciences, Khorramabad, IR Iran. E-mail: a.zendedel@yahoo.com \\ Received 2014 July 12; Accepted 2014 November 24.
}

\begin{abstract}
Background: Genes are involved in the control of stem cell self-renewal as a new class of molecular markers of cancer.

Objectives: In this study, the expression of Oct4, Nanog and Sox2 in cell lines MIA Paca-2, PA-TU-8902 and AsPC-1 and pancreatic cancer tissue were examined.

Materials and Methods: In this experimental study, cell lines, MIA Paca-2, PA-TU-8902 and AsPC-1, were cultured in DMEM (Dulbecco's Modified Eagles Medium) and RPMI-1640 (Roswell Park Memorial Institute) containing FBS 10\% (fetal bovine serum) in a $37^{\circ} \mathrm{C}$ incubator containing $\mathrm{CO}_{2} 5 \%$ and humidity $90 \%$. Samples of tumor and non-cancer pancreatic tumor were purchased Iran tumor bank. Extraction of RNA and synthesis of cDNA was performed. Expression levels of Oct4, Nanog and Sox2 were determined using Real-time PCR. The protein expression levels of target genes in the cell lines were studied by flow cytometry and immunocytochemistry.

Results: The expression rate of Oct4, Nanog and Sox 2 is more in the cancer cell lines than those in the control (normal tissue) samples. The protein expression levels of target genes in the cell lines were confirmed by flow cytometry and immunocytochemistry.

Conclusions: The genes are involved in stem cell self-renewal as a new class of molecular markers of cancer that detected in the pancreatic cell lines. Maybe, these genes play important role in the uncontrolled proliferation of cancer cells.

Keywords: Pancreatic, Nanog, Tumor
\end{abstract}

\section{Background}

Despite advances in cancer molecular biology, cancer remains fatal disease with high mortality rate. In despite modern methods of diagnosis and treatment of cancer, mortality rate of cancer is high. Cancer patients with five years survival rates are still not much different than in the past. Important steps have been taken in the field of cancer biology. Nowadays, many cancer-related gene changes and enzymatic pathways of cancer are known. The researchers predict that treatment based on molecular targets will have a special place in the treatment of cancer in the future (1-5). Pancreatic cancer is one of the most malignant cancers, and the only cure is surgery (6). Pancreatic cancer is resistance the most common treatments such as chemotherapy and radiation (7-9).

Stem cells are found in many tissues of the body and play important role its physiology. Stem cells have three distinct features: self-renewal, the ability to transform into multiple lineages and the ability to proliferate extensively. Stem cells are unique because of the combination of these three properties. Stem cell self-renewal defects seem important because of may be related to carcinogen- esis and cancer. Increased self-renewal defects, in combination with the inherent power of stem cells may be the cause of many malignancies $(3,10)$.

Exit of cancer stem cells from normal cycle (self-renewal) and taking their uncontrolled proliferation is cause cancer formation. Knowledge of signaling pathways controlling of cancer stem cells disorder and recognition cancer stem cells biology are necessary. Understanding cancer stem cell signaling pathways and relation with stem cells need to applied research. The cancer cells during treatment gain resistance to treatment. Resistance to treatment led to rapid progress of cancer. These problems led to defect on cancer treat.

Researchers have shown that stem cell properties, especially the properties described above, are associated with certain types of human cancer. The properties of cancer cells in blood, breast and brain have been identified. Three features of tumor cells including self-renewal, differentiation and proliferation have similar to normal stem cells. Malignant cells with functional properties mentioned above are called "cancer stem cells" $(1-3,11)$.

Copyright (C) 2015, Zahedan University of Medical Sciences. This is an open-access article distributed under the terms of the Creative Commons Attribution-NonCommercial 4.0 International License (http://creativecommons.org/licenses/by-nc/4.0/) which permits copy and redistribute the material just in noncommercial usages, provided the original work is properly cited. 
The POU5F1 gene called Oct4 or Oct3 is also known (12). OCT4 in humans is located on chromosome 6p21/1 (13). This gene is expressed in embryonic pluripotent structures. Researchers showed that Oct4 gene expressed in different human cancer cells and tumor tissues. It seems Oct4 plays an important role in tumor genesis $(14,15)$.

Sox 2 gene is one of the most important transcription factors that regulate self-renewal of embryonic stem cells. Sox 2 is an HMG family of proteins. Sox2 gene lacks introns and has cofactor role in the transcription of target genes Oct4. Sox 2 is essential for pluripotency and maintaining the proliferative potential of stem cells (16). Sox2 is expressed in neural stem cells, precursors and in a small number of neurons $(17,18)$. Researchers showed that Sox2 plays an important role in related to cancer (19-21).

Studies have shown that Nanog regulate self-renewal, preserve pluripotency and activate transcription in the inner cell mass (ICM) and embryonic stem cells. Nanog play important role in reprogramming differentiated cells. NANOG promoter is a direct target Oct4/Sox2 complex $(22,23)$.

Genes Oct4, Nanog and Sox2 make a strong transcription regulatory circuit. Keep this regulatory circuit facilitates cell pluripotency and helps to regulate the self-renewal of embryonic stem cells. Each of these three genes involved in the regulation of other genes. The three genes as transcriptional activator of other genes involved in self-renewal as well as genes involved in the differentiation inhibition $(4,24,25)$. Some studies have shown that these factors may have a role in human malignant cancer $(22,23,26,27)$.

Cancer stem cells have very high tumor genesis power. Cancer stem cells have intrinsic resistances to conventional methods of treatment. Cancer stem cells are associated with tumor characteristics, including tumor recurrence, tumor progression, metastasis and resistance to chemotherapy. So today has been studied for the treatment and diagnosis of cancer. Due to some weakness in conventional treatment of cancer using molecular markers has become increasingly important. The sensitivity of molecular markers can also facilitate cancer diagnosis and classification of patients to use medical procedures may have contributed $(10,28-30)$.

\section{Objectives}

The aim of this study was to investigate the expression of genes Oct4, Nanog and Sox 2 in pancreatic cancer cell lines and pancreatic tumor tissue. Expression of these genes can be used as a marker for cancer stem cell hypothesis. This theory may in future play an important role in the diagnosis and treatment of cancer.

\section{Materials and Methods}

In this experimental study, pancreatic cancer cell lines, MIA Paca-2 (NCBI code: C459), PA-TU-8902 (NCBI code: C557) and AsPC-1 (NCBI code: C558), and U-87 MG (NCBI code: C531), glioblastoma cell line, were obtained from the Pasteur institute of Iran. NT2 cell line is a human embryonic carcinoma cell line. NT2 were used as positive control genes for Oct4 and Nanog. NT2 cell line was obtained from Sanandaj University of Medical Sciences. U87 MG cell line was used as a positive control for Sox2 gene. Cell lines were cultured in DMEM (Dulbecco's Modified Eagles Medium) and RPMI-1640 (Roswell Park Memorial Institute) containing FBS 10\% (fetal bovine serum) in a $37^{\circ} \mathrm{C}$ incubator containing $\mathrm{Co}_{2} 5 \%$ and humidity $90 \%$. Samples of tumor and non-cancer pancreatic tumor were purchased Iran tumor bank.

\subsection{RNA Isolation and cDNA Synthesis}

Extraction of RNA was performed by RNeasy mini kit, according to manufactory company catalog (Qiagen, Cat. no. 74104). The purity and concentration of RNA was performed by measuring the absorbance at $260 \mathrm{~nm}$ (A260) in a spectrophotometer. cDNA synthesis was performed by the unique QuantiTect reverse transcription kit, according to manufactory company catalog (Qiagen, Cat. no. 205311). Concentrations of RNA $(\mu \mathrm{g} / \mu \mathrm{L})$ were between $1.2-1.4$ and purity of RNA (Absorbance $260 / 280 \mathrm{~nm}$ ) was between $1.8-2$.

\subsection{Real-Time PCR}

Real-time PCR was performed use applied bioscience 7500 fast with SYBR green detection for gene expression analysis. Forty reaction amplification cycles was performed. Each reaction cycle consisted of: 60 seconds at $95^{\circ} \mathrm{C}, 15$ seconds at $60^{\circ} \mathrm{C}$ and 60 seconds at $72^{\circ} \mathrm{C}$. Control mixture consisted of PCR mixture without cDNA. $\beta$-actin gene was used as an internal control. For Nanog the primers were as follows: Nanog foreward: 5'-GGTGGAGTATGGTTGGAGCC-3'; Nanog reverse: 5'-GAGACGGCAGCCAAGGTTAT-3' (reference genbank: NM-024865). For Sox2 the primers were as follows: Sox2 foreward: 5'-CAGGAGTTGTCAAGGCAGAGA-3'; Sox2 reverse: 5'-CCGCCGCCGATGATTGTTAT-3' (reference genbank: NM-003106). For Oct4 the primers were as follows: Oct4 foreward: 5'-CTGGGGGTGATACTTGAGTGA-3'; Oct4 reverse: 5'-GTTCGCTTTCTCTTTCGGGC-3' (reference genbank: NM-203289). For b-actin the primers were as follows: b-actin foreward: 5'-GGTCGTACCACTGGCATTGT-3'; b-actin reverse: 5'-ACGCACGATTTCCCTCTCAG-3' (reference genbank: NM_031144.3).

\subsection{Immunocytochemistry}

To investigate proteins Oct4 (Santa Cruz, H-134: sc-9081), Nanog (Santa Cruz, 5A10: sc-134218) and Sox2 (Santa Cruz, sc-17319 X) were used immunocytochemistry techniques according of Aminietal.method $\square \square$ 's.Afterfixationon paraformaldehyde $4 \%$ (30 minutes, $4^{\circ} \mathrm{C}$ ), cells wash twice with PBS and incubated on triton-X100 4\%-PBS for 5 - 15 minutes. For inhibition of non-specific bands, samples incubated on goat serum $5 \%$. Samples incubated overnight in 
Oct-4, Sox-2 and Nanog primary antibody (diluted 1:200 with PBS-BSA 2\%). After 3 times washing, samples 3 hours incubated with goat anti-rabbit (diluted 1:100 with PBSBSA $2 \%$ ). For nuclear staining, cells incubated on $1 \mu \mathrm{g} / \mathrm{mg}$ DAPI solution for 10 minutes. U87MG NT2 cell lines used as positive controls. Primary antibody was omitted for negative control samples. The samples were analysis with fluorescence microscopy (31).

\subsection{Flow Cytometry}

Cell suspension centrifuged (5 minutes, $1500 \mathrm{rpm}$ ) and supernatant discard. Cell fixation applied. After fixation with paraformaldehyde $4 \%\left(4^{\circ} \mathrm{C}\right)$, cells incubated with triton X-100. Cells washed twice with goat serum. Samples incubated overnight in Oct-4, Sox-2 and Nanog primary antibody (diluted 1:200 with PBS-BSA 2\%). After 3 times washing, samples 45 minutes incubated with goat anti-rabbit (diluted 1:100 with PBS-BSA 2\%). Cell suspension analyses were performed using Partec flow cytometry (32).

Biological meaningful results of real-time PCR analyzed with student's t-test and SPSS-22 software. Results considered significant at $\mathrm{P} \leq 0.05$.

\section{Results}

\subsection{Real-time PCR}

Oct4 gene expression was observed in tumor cell lines and normal and tumor tissues (Figure 2). However, the expression levels of this gene in the category AsPC- 1 are more than other cell lines and pancreatic tumor tissue (Figure 2). The expression levels of Oct4 gene was less in PATU-8902 cell line than others (Figure 2).

Expression of Nanog gene was detected in all of cell lines and tissues (normal and pancreatic tumor). The expression levels of Nanog are more in the category AsPC-1 and pancreatic tumor tissue than other cell lines (Figure 3). Sox 2 gene expression is more in pancreatic tumor tissues and AsPC-1 cell line than other (Figure 4).

\subsection{Flow Cytometry}

Maximum and minimum Nanog protein expression was observed in AsPC-1 and MIA Paca-2 cell lines, respectively (Figure 5). Nanog protein expression was slightly observed in normal tissues (Figure 5). Maximum and minimum Sox2 protein expression was observed in AsPC1 and PA-TU-8902 cell lines, respectively (Figure 5). Level of Sox2 protein in pancreatic cancer tissues was relatively high (Figure 5). Maximum Oct4 protein expression was observed in MIA Paca-2 cell line (Figure 5). Like others, this protein was slightly expressed in the normal pancreatic tissue (Figure 5).

\subsection{Immunocytochemistry}

Immunocytochemistry results are presented with a qualitative method. Oct4 and Sox 2 proteins expression were detected in AsPC-1, MIA Paca-2 and PA-TU-8902 cancer cell lines (Figure 6 and Figure 7). Nanog protein expression was very weak detected in MIA Paca-2 and PA-TU-8902 cancer cell lines (Figure 8). Nanog protein expression was well detected in AsPC-1 cancer cell line (Figure 8).

Figure 1. Gel Electrophoresis Obtained From Pancreatic Cancer Cell Extracted RNA

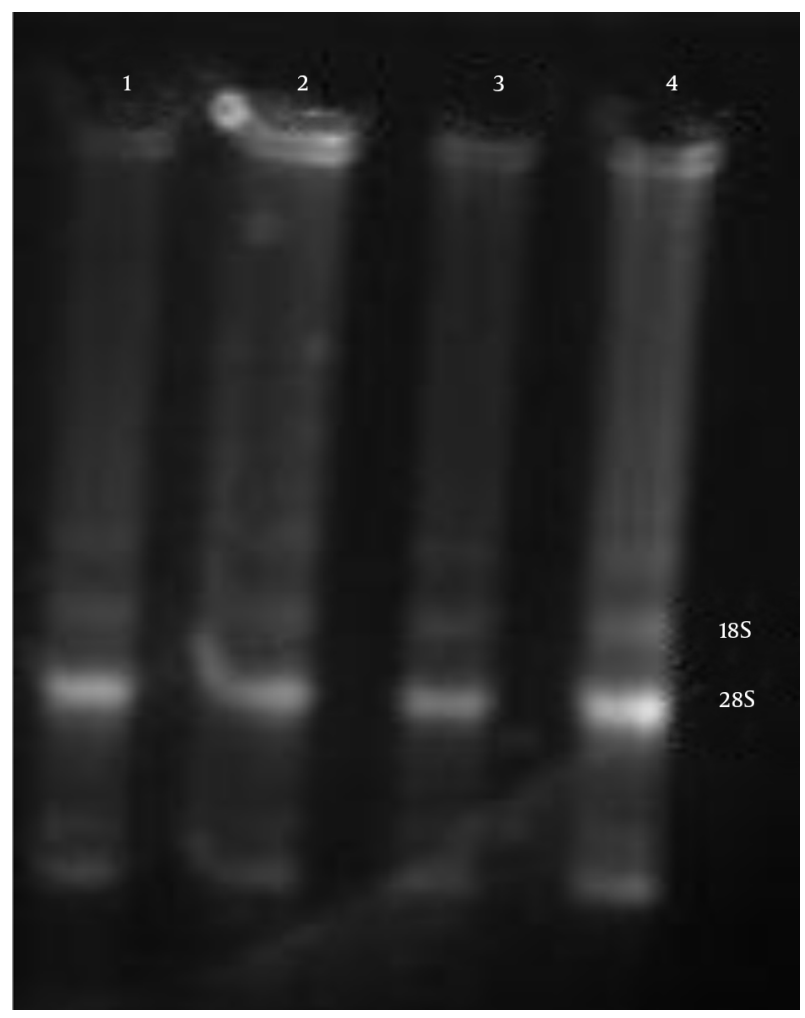

RNA of cell lines MIA Paca-2, PA-TU-8902 and AsPC-1 transferred to agarose gel; the presence of $18 \mathrm{~S}$ and $28 \mathrm{~S}$ bands on agarose gel showed that RNA degradation was not observed. 1, 2, 3 and 4 showed cell lines MIA Paca-2, PA-TU-8902, AsPC-1 and pancreatic tumors, respectively.

Figure 2. Oct4 Expression in Pancreatic Cell Lines

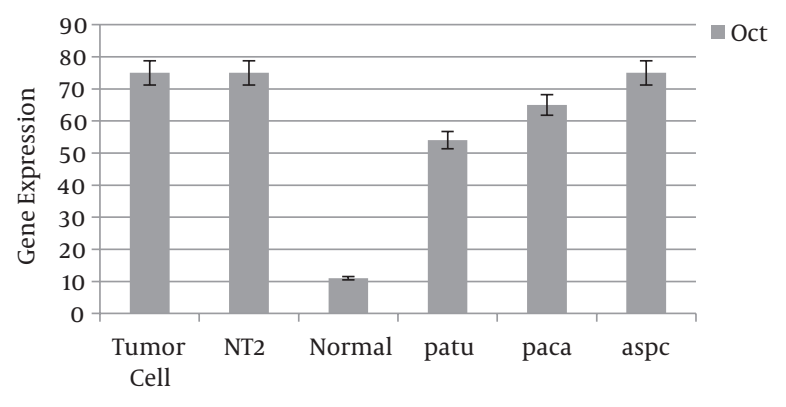

NT2 cell line used as positive control. Tumor cells extracted from the human pancreatic tissue. 
Assadollahi Vet al.

Figure 3. Nanog Expression in Pancreatic Cell Lines

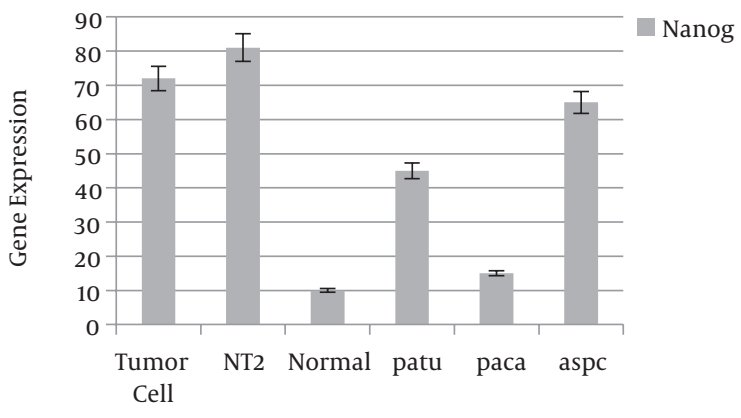

NT2 cell line used as positive control; tumor cells extracted from the human pancreatic tissue.

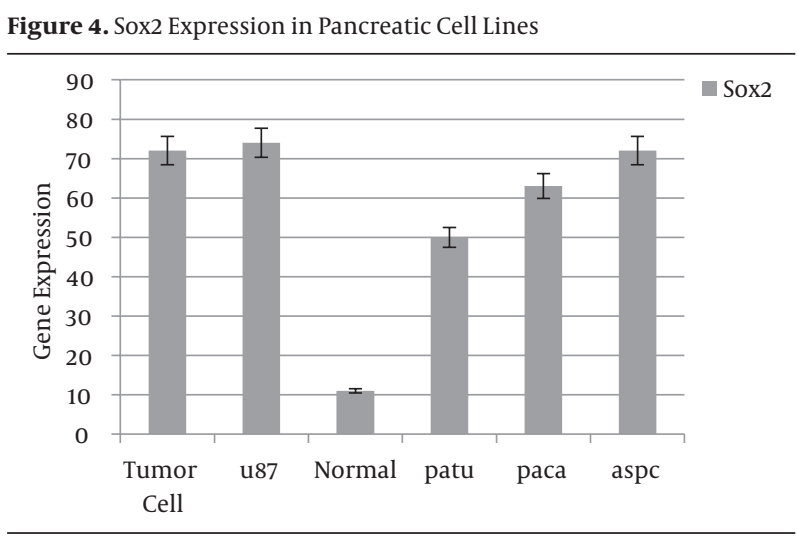

U87 cell line used as positive control; tumor cells extracted from the human pancreatic tissue.

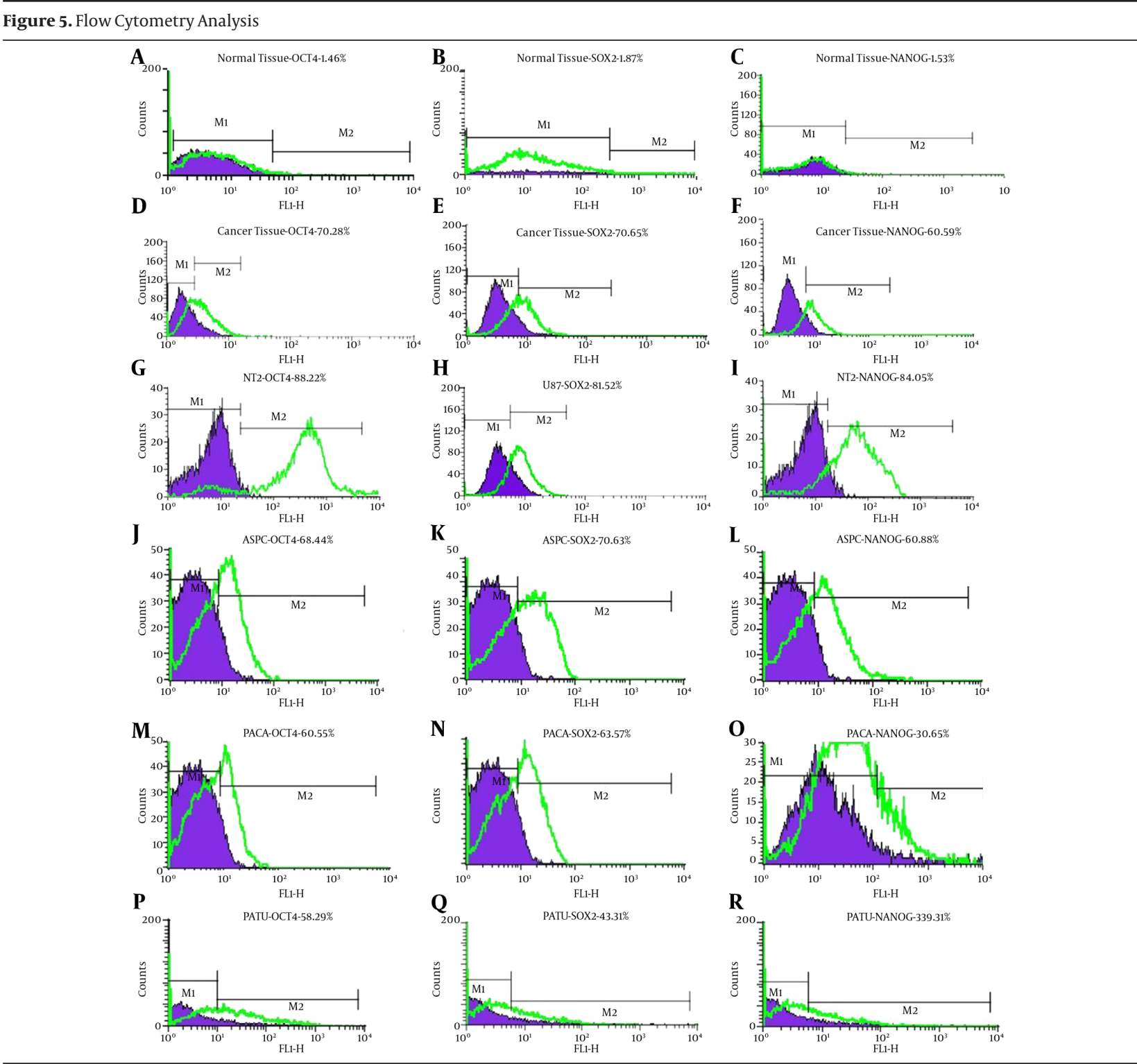

Label of each graph show name of cell line, name of protein and rate of protein detected by flow cytometry, respectively. 
Figure 6. Detection of Oct4 in the Tumor Cell Lines With Immunocytochemistry
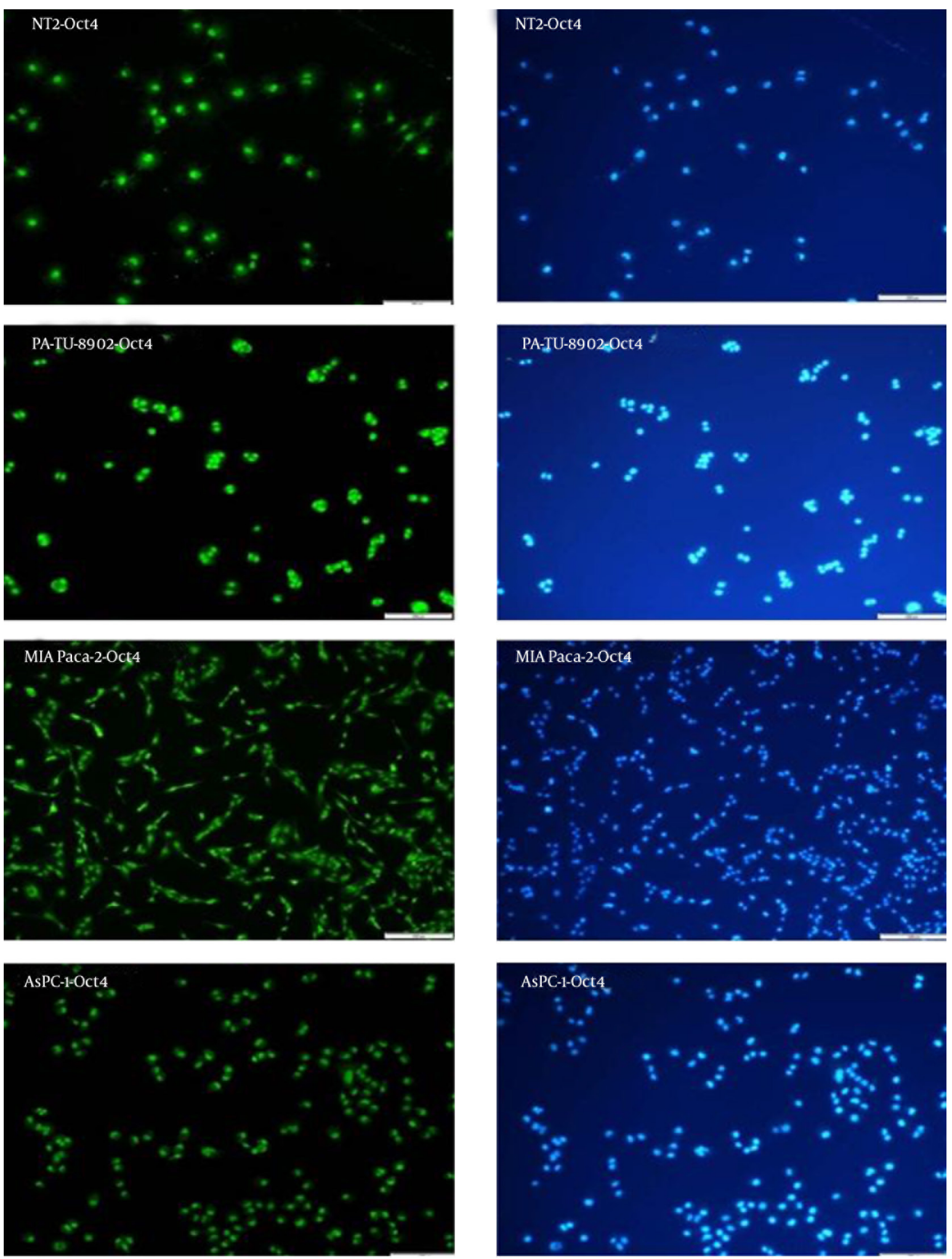

Label of each section show name of cell line, name of protein detected by immunocytochemistry, respectively; DAPI staining used as counter stain. 
Figure 7. Detection of Sox2 in the Tumor Cell Lines With Immunocytochemistry
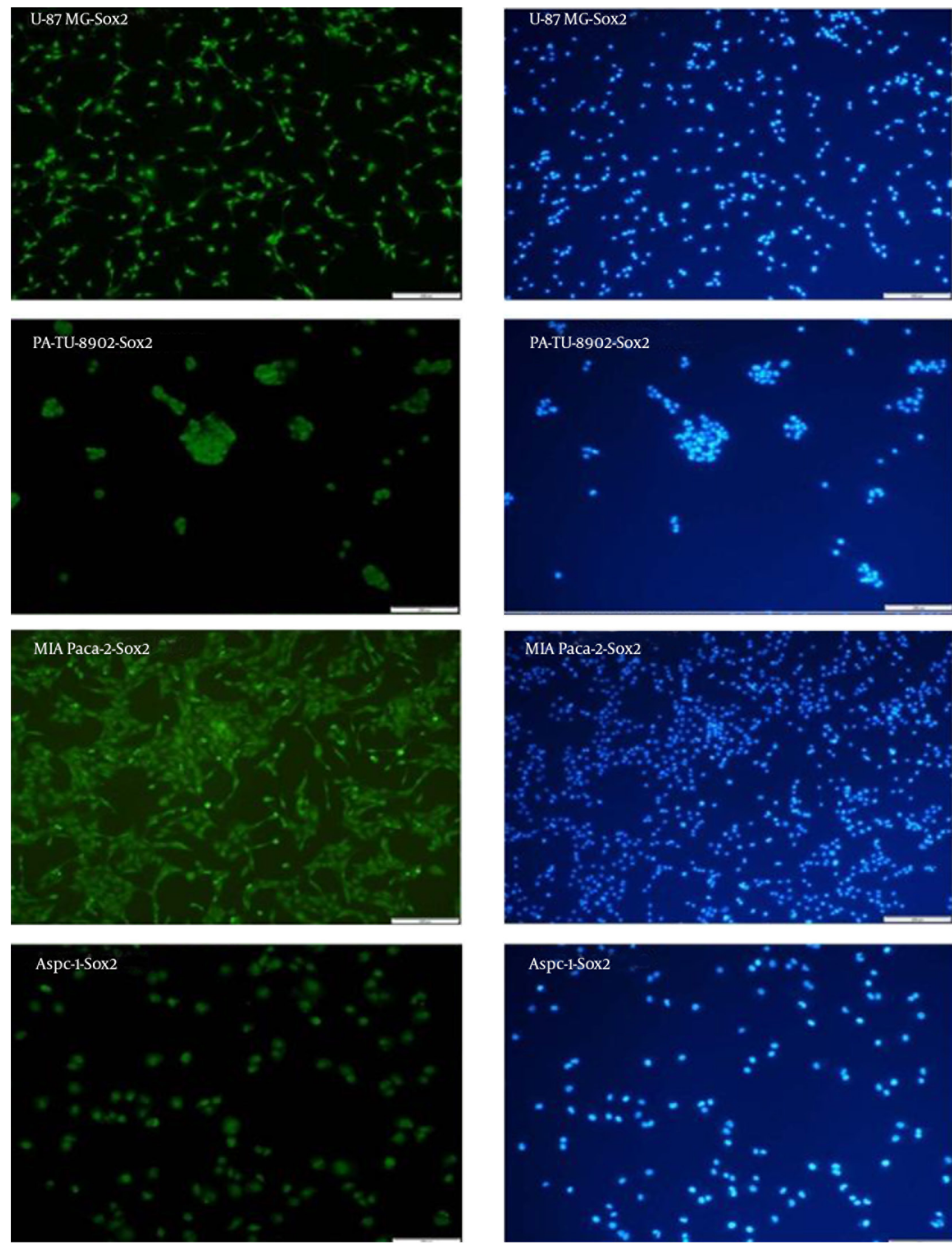

Label of each section show name of cell line, name of protein detected by immunocytochemistry, respectively; DAPI staining used as counter stain. 
Figure 8. Detection of Nanog in the Tumor Cell Lines With Immunocytochemistry
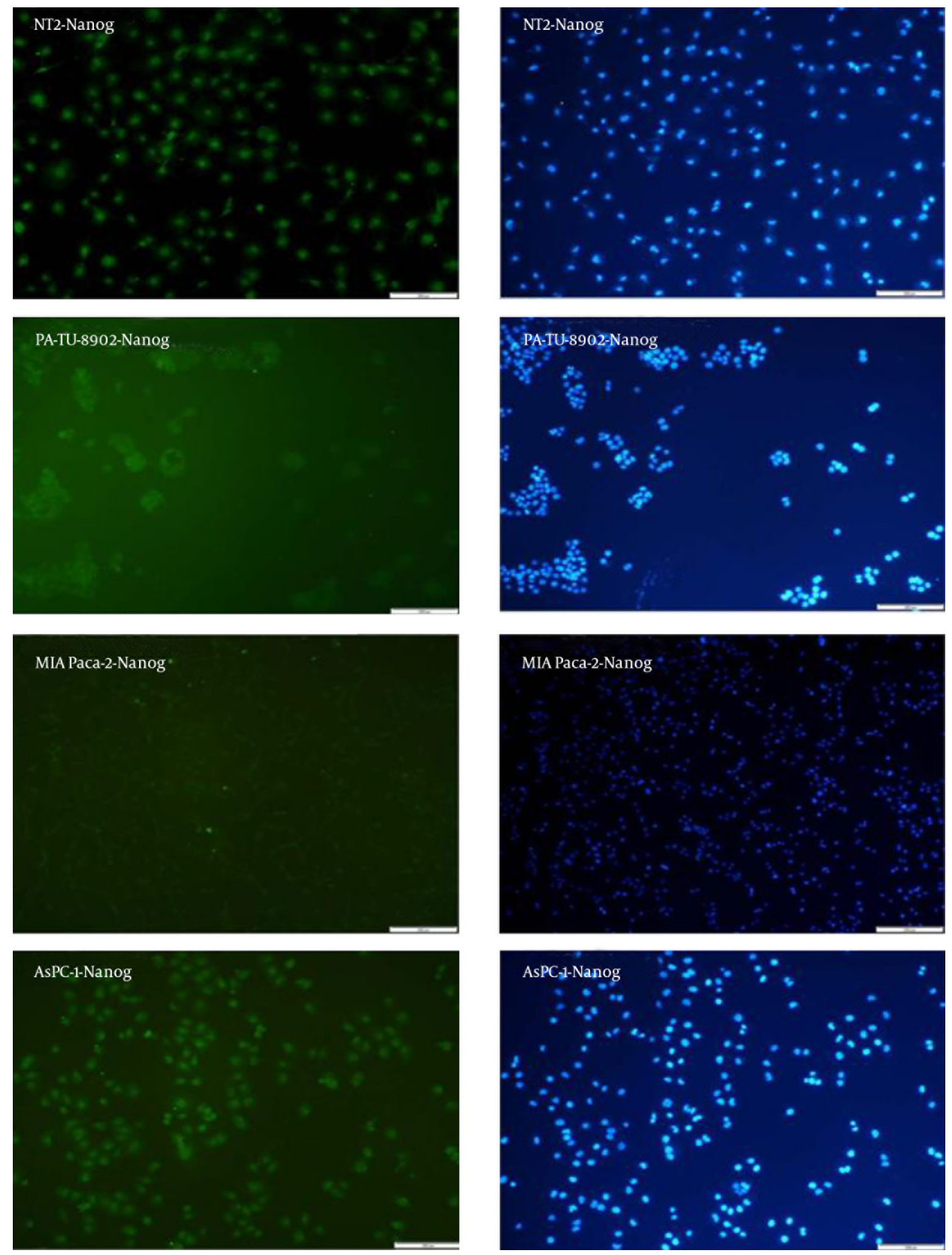

Label of each section show name of cell line, name of protein detected by immunocytochemistry, respectively; DAPI staining used as counter stain. 


\section{Discussion}

The results of this study showed expression of Oct4, Nanog and Sox 2 in pancreatic cancer cell lines and pancreatic human tumor samples for the first time. Today, the genes that are involved in stem cell self-renewal have been introduced as a new class of molecular markers of cancer that play important role in the uncontrolled proliferation of cancer cells $(28,29)$.

Oct4 is one of the most important genes that control the process of self-renewal and differentiation of embryonic stem cells (33). Oct4 expression assist in controlling cancer cells self-renewal and inhibits differentiation (12). Researcher suggested that Oct4 play new molecular role for the identification of new prognostic factor for recurrence and classification of patients for appropriate treatment. Oct4 was expressed in many cancers such as GCTS (14), Tumor cell lines of colon, liver, prostate bladder and breast $(23,25,31,34,35)$. The results of this study showed expression of Oct4 in pancreatic cancer cell lines and pancreatic human tumor samples. These results are consistent with results from other researchers.

Nanog molecular marker is another key factor in keeping pluripotency of stem cells. Nanog play important role in regulating self-renewal and maintenance of stem cells. Nanog is essential for reprogramming differentiated cells (36). Nanog expression is also seen in human tumors and embryonic carcinoma (23). Amini et al. showed that Nanog expressed in human colon cell lines and tumor samples (31). Nanog expressed in embryonic stem cells and not in differentiated cells (23). Nanog is also necessary for activities self-renewal gene such as REX1 (36). Recently, cytoplasmic expression of Nanog has also been reported in breast cancer (23). The results of this study confirm Nanog expression in the pancreatic cancer cell lines and pancreatic tissue cancers.

Sox2 is another genetic marker gene expression was examined in this study. Sox 2 gene regulating neurogenesis in the developing fetal nervous system and plays a key role in maintaining neural stem cells proliferation and differentiation (17). Increased Sox2 expression observed in patients with ovarian carcinoma and melanoma cancers (27). Sox2 expression has been reported in embryonic stem cells and one of the most important transcription factors that are involved in the regulation of embryonic stem cell self-renewal (37). Sox2 is expressed in several types of tumor tissue such as bladder, brain and liver $(21,26,27)$.

The results of our study indicated Sox 2 gene expression for the first time in pancreatic cancer cell lines. Studies have shown that Oct4 expression regulates of Nanog expression via binding sites in the promoter of Nanog. Sox 2 is involved as cofactor in Oct4 target genes transcription. Oct4 interact with Sox2 to regulate downstream target genes. Binding site exist in Nanog promoter for Oct4-Sox2 complex. Rex1 gene is required for stem cell self-renewal. Rex1 is activated by Nanog and Rex1 is downstream target gene Oct4-Sox2 complex $(25,38)$.
Schoenhals et al. showed simultaneous expression of Oct4 and Sox2 in tumor tissues such as brain, bladder and lung (27). Freberg et al. demonstrated that three genes Oct4, Nanog and Sox2 simultaneously expressed in embryonic cancer cells (22). Matsuoka et al. showed Simultaneous expression Oct4, Nanog and Sox2 in gastric cancer (39). Amini et al. showed as well as the expression of the Oct4, Nanog and Sox2 in colon cancer (31). Schulz and Hoffmann demonstrated that three genes Oct2, Nanog and Sox 2 expressed in embryonic stem cells and testicular cancer cells (40). Recently, researcher showed that human pancreatic cancer tissue express Sox2 (41), Oct4 and Nanog (42). However, the function of Sox2, Oct4 and Nanog in pancreatic cancer cells are ambiguous. Taken together, Oct4, Nanog and Sox2 are created a strong transcriptional circuit for pluripotency and self-renewal of stem cells. Each of these three genes involved in the regulation of other genes. The genes are involved in stem cell self-renewal as a new class of molecular markers of cancer that detected in the pancreatic cell lines. Maybe, these genes play important role in the uncontrolled proliferation of cancer cells. Secret of cancer, some of the cells have the characteristics of cancer stem cells. These genes have a major role to support the theory of cancer stem cell. These genes potentially could be used as a marker for tumor diagnosis or prognosis of cancer.

\section{Acknowledgments}

This study approved with grant number 1307 in the Lorestan University of Medical Sciences. Authors thank Lorestan University of Medical Sciences for the financial support.

\section{Footnotes}

Authors' Contribution:All authors had equal role in design, work, statistical analysis and manuscript writing.

Conflict of Interest:The authors declare no conflict of interest.

Funding/Support:Authors thank Lorestan University of Medical Sciences, Khorramabad, Iran for the financial support.

\section{References}

1. Reya T, Morrison SJ, Clarke MF, Weissman IL. Stem cells, cancer, and cancer stem cells. Nature. 2001;414(6859):105-11. doi: 10.1038/35102167. [PubMed: 11689955]

2. Jordan CT, Guzman ML, Noble M. Cancer stem cells. N Engl J Med. 2006;355(12):1253-61. doi: 10.1056/NEJMra061808. [PubMed: 16990388]

3. Pardal R, Clarke MF, Morrison SJ.Applying the principles of stemcell biology to cancer. Nat Rev Cancer. 2003;3(12):895-902. doi: 10.1038/nrc1232. [PubMed:14737120]

4. Wicha MS, Liu S, Dontu G. Cancer stem cells: an old idea-a paradigm shift. Cancer Res. 2006;66(4):1883-90. doi: 10.1158/00085472.CAN-05-3153. [PubMed:16488983]

5. Sagar J, Chaib B, Sales K, Winslet M, Seifalian A. Role of stem cells in cancer therapy and cancer stem cells: a review. Cancer Cell Int. 2007;7:9. doi:10.1186/1475-2867-7-9. [PubMed:17547749]

6. Siegel R, Naishadham D, Jemal A. Cancer statistics, 2012. CA Cancer J Clin. 2012;62(1):10-29. doi:10.3322/caac.20138. [PubMed:22237781] 
7. Castellanos E, Berlin J, Cardin DB. Current treatment options for pancreatic carcinoma. Curr Oncol Rep. 2011;13(3):195-205. doi: 10.10 07/s11912-011-0164-1. [PubMed: 21491194]

8. Costello E, Neoptolemos JP. Pancreatic cancer in 2010: new insights for early intervention and detection. Nat Rev Gastroenterol Hepatol. 2011;8(2):71-3. doi: 10.1038/nrgastro.2010.214. [PubMed: 21293504]

9. Kim EJ,Simeone DM. Advances in pancreatic cancer. Curr Opin Gastroenterol. 2011;27(5):460-6. doi: 10.1097/MOG.0b013e328349e31f. [PubMed: 21778878]

10. Al-Hajj M, Clarke MF. Self-renewal and solid tumor stem cells. Oncogene. 2004;23(43):7274-82. doi: 10.1038/sj.onc.1207947. [PubMed: 15378087]

11. Dean M, Fojo T, Bates S. Tumour stem cells and drug resistance. Nat Rev Cancer. 2005;5(4):275-84. doi: 10.1038/nrc1590. [PubMed: 15803154]

12. Scholer HR, Ruppert S, Suzuki N, Chowdhury K, Gruss P. New type of POU domain in germ line-specific protein Oct-4. Nature. 1990;344(6265):435-9. doi: 10.1038/344435a 0. [PubMed: 1690859]

13. Pesce M, Scholer HR. Oct-4: gatekeeper in the beginnings of mammalian development. Stem Cells. 2001;19(4):271-8. doi: 10.1634/stemcells.19-4-271. [PubMed:11463946]

14. Looijenga LH, Stoop H, de Leeuw HP, de Gouveia Brazao CA, Gillis AJ, van Roozendaal KE, et al. POU5F1 (OCT3/4) identifies cells with pluripotent potential in human germ cell tumors. Cancer Res. 2003;63(9):2244-50. [PubMed:12727846]

15. Cheng L. Establishing a germ cell origin for metastatic tumors using OCT4 immunohistochemistry. Cancer. 2004;101(9):200610. doi: $10.1002 /$ cncr.20566. [PubMed: 15386301]

16. Chambers I, Colby D, Robertson M, Nichols J, Lee S, Tweedie S, et al. Functional expression cloning of Nanog, a pluripotency sustaining factor in embryonic stem cells. Cell. 2003;113(5):643-55. [PubMed: 12787505$]$

17. Ferri AL, Cavallaro M, Braida D, Di Cristofano A, Canta A, Vezzani A, et al. Sox2 deficiency causes neurodegeneration and impaired neurogenesis in the adult mouse brain. Development. 2004;131(15):3805-19. doi: 10.1242/dev.01204. [PubMed:15240551]

18. Graham V, Khudyakov J, Ellis P, Pevny L. SOX2 functions to maintain neural progenitor identity. Neuron. 2003;39(5):749-65. [PubMed: 12948443]

19. Xiang R, Liao D, Cheng T, Zhou H, Shi Q, Chuang TS, et al. Downregulation of transcription factor SOX2 in cancer stem cells suppresses growth and metastasis of lung cancer. Br J Cancer. 2011;104(9):1410-7. doi:10.1038/bjc.2011.94. [PubMed: 21468047]

20. Lengerke C, Fehm T, Kurth R, Neubauer H, Scheble V, Muller F, et al. Expression of the embryonic stem cell marker SOX2 in earlystage breast carcinoma. BMC Cancer. 2011;11:42. doi: 10.1186/14712407-11-42. [PubMed:21276239]

21. Gangemi RM, Griffero F, Marubbi D, Perera M, Capra MC, Malatesta $\mathrm{P}$, et al. SOX2 silencing in glioblastoma tumor-initiating cells causes stop of proliferation and loss of tumorigenicity. Stem Cells. 2009;27(1):40-8. doi: 10.1634/stemcells.2008-0493. [PubMed:18948646]

22. Freberg CT, Dahl JA, Timoskainen S, Collas P. Epigenetic reprogramming of OCT4 and NANOG regulatory regions by embryonal carcinoma cell extract. Mol Biol Cell. 2007;18(5):1543-53. doi: 10.1091/mbc.E07-01-0029. [PubMed:17314394]

23. Ezeh UI, Turek PJ, Reijo RA, Clark AT. Human embryonic stem cell genes OCT4, NANOG, STELLAR, and GDF3 are expressed in both seminoma and breast carcinoma. Cancer. 2005;104(10):2255-65. doi:10.1002/cncr.21432. [PubMed:16228988]

24. Avery S, Inniss K, Moore H. The regulation of self-renewal in human embryonic stem cells. Stem Cells Dev. 2006;15(5):729-40. doi: 10.1089/scd.2006.15.729. [PubMed:17105408]

25. Rodda DJ, Chew JL, Lim LH, Loh YH, Wang B, Ng HH, et al. Transcriptional regulation of nanog by OCT4 and SOX2.JBiol Chem.2005;280(26):24731-
7. doi:10.1074/jbc.M502573200. [PubMed: 15860457]

26. Ben-Porath I, Thomson MW, Carey VJ, Ge R, Bell GW, Regev A, et al. An embryonic stem cell-like gene expression signature in poorly differentiated aggressive human tumors. Nat Genet. 2008;40(5):499-507. doi:10.1038/ng.127. [PubMed:18443585]

27. Schoenhals M, Kassambara A, De Vos J, Hose D, Moreaux J, Klein B. Embryonic stem cell markers expression in cancers. Biochem Biophys Res Commun. 2009;383(2):157-62. doi: 10.1016/j. bbrc.2009.02.156. [PubMed:19268426]

28. Gostjeva EV, Thilly WG. Stem cell stages and the origins of colon cancer: a multidisciplinary perspective. Stem Cell Rev. 2005;1(3):243-51. doi: 10.1385/scr:1:3:243. [PubMed: 17142861]

29. Clarke MF, Fuller M. Stem cells and cancer: two faces of eve. Cell. 2006;124(6):1111-5. doi: 10.1016/j.cell.2006.03.011. [PubMed: 16564000]

30. Haraguchi N, Inoue H, Tanaka F, Mimori K, Utsunomiya T, Sasaki A, et al. Cancer stem cells in human gastrointestinal cancers. Hum Cell. 2006;19(1):24-9. doi: 10.1111/j.1749-0774.2005.00004.x. [PubMed:16643604]

31. Amini S, Fathi F, Parivar K, Kuchesfahani HM, Rezaie MJ, Nikkhoo B. Evaluating the expression of Oct4, NANOG, Sox2 and nucleostemin in colon cancer cell lines (Caco-2 and HT-29). Yakhteh Med J.2010;12(2):223-30.

32. Saheli M, Hosseini A, Piryaei A, Fadaei Fathabadi F, Bandehpour $\mathrm{M}$, Salehi M, et al. Evaluation of the differentiation process of human bone marrow mesenchymal stem cells to cardiomyocytelike cells: An in vitro study. J Iran Anat Sci. 2011;9(36):179-90.

33. Tai MH, Chang CC, Kiupel M, Webster JD, Olson LK, Trosko JE. Oct4 expression in adult human stem cells: evidence in support of the stem cell theory of carcinogenesis. Carcinogenesis. 2005;26(2):495-502. doi: 10.1093/carcin/bgh321. [PubMed: 15513931]

34. Atlasi Y, Mowla SI, Ziaee SA, Bahrami AR. OCT-4, an embryonic stem cell marker, is highly expressed in bladder cancer. Int $J$ Cancer. 2007;120(7):1598-602. doi: 10.1002/ijc.22508. [PubMed: 17205510]

35. Amini S, Fathi F, Mobalegi J, Sofimajidpour H, Ghadimi T. The expressions of stem cell markers: Oct4, Nanog, Sox2, nucleostemin, Bmi, Zfx, Tcl1, Tbx3, Dppa4, and Esrrb in bladder, colon, and prostate cancer, and certain cancer cell lines. Anat Cell Biol. 2014;47(1):1-11. doi: 10.5115/acb.2014.47.1.1. [PubMed: 24693477]

36. Liu N, Lu M, Tian X, Han Z. Molecular mechanisms involved in self-renewal and pluripotency of embryonic stem cells. J Cell Physiol. 2007;211(2):279-86. doi: 10.1002/jcp.20978. [PubMed: 17195167]

37. Chambers I, Smith A. Self-renewal of teratocarcinoma and embryonic stem cells. Oncogene. 2004;23(43):7150-60. doi: 10.1038/ sj.onc.1207930. [PubMed:15378075]

38. Luu HH, Zhang R, Haydon RC, Rayburn E, Kang Q, Si W, et al. Wnt/ beta-catenin signaling pathway as a novel cancer drug target. Curr Cancer Drug Targets. 2004;4(8):653-71. [PubMed: 15578921]

39. Matsuoka J, Yashiro M, Sakurai K, Kubo N, Tanaka H, Muguruma $\mathrm{K}$, et al. Role of the stemness factors sox 2 , oct3/4, and nanog in gastric carcinoma. J Surg Res. 2012;174(1):130-5. doi: 10.1016/j. jss.2010.11.903. [PubMed: 21227461]

40. Schulz WA, Hoffmann MJ. Transcription factor networks in embryonic stem cells and testicular cancer and the definition of epigenetics. Epigenetics. 2007;2(1):37-42. [PubMed: 17965618]

41. Herreros-Villanueva M, Zhang JS, Koenig A, Abel EV, Smyrk TC, Bamlet WR, et al. SOX2 promotes dedifferentiation and imparts stem cell-like features to pancreatic cancer cells. Oncogenesis. 2013;2:e61. doi:10.1038/oncsis.2013.23. [PubMed: 23917223]

42. Lu Y, Zhu H, Shan H, Lu J, Chang X, Li X, et al. Knockdown of Oct4 and Nanog expression inhibits the stemness of pancreatic cancer cells. Cancer Lett. 2013;340(1):113-23. doi: 10.1016/j.canlet.2013.07.009. [PubMed: 23872274] 